\title{
Дисфункция височно-нижнечелюстного сустава и боль
}

\author{
Д. К. Али-заде ${ }^{1}$ \\ ${ }^{1}$ Центральная Клиническая Больница \\ jamila_alizade@yahoo.com
}

Дисфункция височно-нижнечелюстного сустава (ВНЧС) представляет собой дислокацию диска, которая часто обнаруживается методом магнитно-резонансной томографии (МРТ). Основным симптомом дисфункции является боль. В данном исследовании проведена корреляция между болью в области ВНЧС и дислокацией диска.

Ключевые слова: дисфункция височно-нижнечелюстного сустава, магнитно-резонансная томография, боль.

Нарушения височно-нижнечелюстного сустава (ВНЧС) зачастую проявляются такими клиническими симптомами как боль в суставе и снижением силы, девиацией нижней челюсти при открывании рта, возникновением звуков в суставе, головная и ушная боль [1]. Внутреннее нарушение ВНЧС представляет собой дислокацию суставного диска с редукцией или без редукции при открывании рта [2].

Боль, как правило, является самым главным и самым раздражающим симптомом. Зачастую, причинами вызывающими боль являются парафункциональные привычки, депрессия, лечение у стоматолога [3].

Магнитно-резонансная томография (МРТ) является золотым стандартом для диагностики изменений ВНЧС, обеспечивая прекрасное контрастирование мягких тканей, без применения радиационной нагрузки и хирургического вмешательства $[4,5,6]$.

Однако известно, что иногда симптомы или жалобы пациентов могут быть несовместимы с результатами МРТ. В этом исследовании была выявлена связь между МРТ признаками и симптомами пациента.
Материалы и методы исследования. Исследование проводилось в Центральной Клинической Больнице города Баку. С апреля 2019 года до марта 2020 года было проведено МРТ 53 пациентам с односторонней болью в области ВНЧС. Предварительно челюстнолицевыми хирургами, ортодонтами и ортопедами тщательно собирался анамнез, где учитывали возникновение и продолжительность симптомов, наличие

парафункциональных привычек, а также психосоматическое состояние пациента. На каждого пациента открывалась анкета, где фиксировалась степень боли по шкале от 0 до 10 $(0=$ нет боли, $10=$ нестерпимая боль $)$.

Магнитно-резонансная томография ВНЧС выполнялась на магнитно-резонансном томографе закрытого типа и индукцией магнитного поля 3.0 Тесла Siemens Magnetom Verio с использованием головной катушки.

Исследование включало в себя получение кососагиттальных изображений в режиме PD, PDFSat в положении зарытого и открытого рта. Толщина среза составляла 2.5 мм с промежутками между ними в 0.2 мм. Также 
было проведено кинематическое исследование сустава для оценки положения диска и мыщелка в 5 различных положениях рта.

Пациенты были разделены на несколько групп : пациенты с нормальным положением диска (НПД) и пациенты с дислокацией диска (ДД). Пациенты с дислокацией диска были разделены на две группы : с редукцией (ДДсР) и без редукции (ДДбР) при открывании рта.

Результаты. Было проведено МРТ исследование 55 пациентов, из которых 51

\begin{tabular}{|l|c|c|c|}
\hline \multirow{2}{*}{ Средний возраст } & НПД & ПДДсР & ПДДбР \\
\cline { 2 - 4 } & 21.8 & 50.9 & 27.2 \\
\hline Пол (ж/м) & $10 / 2$ & $27 / 1$ & $14 / 1$ \\
\hline Инт-ть боли & 5.10 & 7.15 & 7.56 \\
\hline \multirow{2}{*}{ Кол-во пациентов } & 12 & 28 & 15 \\
\hline
\end{tabular}

По шкале оценки боли средний показатель у пациентов с отсутствием дислокации диска составил 5.10. Средний показатель оценки боли у пациентов с дислокацией диска с редукцией составил 7.15, без редукции 7.56. Самой частой причиной возникновения боли выявлены бруксизм (67.4\%), что составило $24 \%$ у пациентов с негативным МРТ результатом, $43.4 \%$ у пациентов с наличием дислокации диска. Далее следует дентальная терапия $(20.8 \%)$ и парафункциональные привычки (11.8 $\%)$.

Из 55 обследованных пациентов у 35 пациентов $(63.63 \%)$ отметили депрессивное настроение и все эти пациенты женщины.

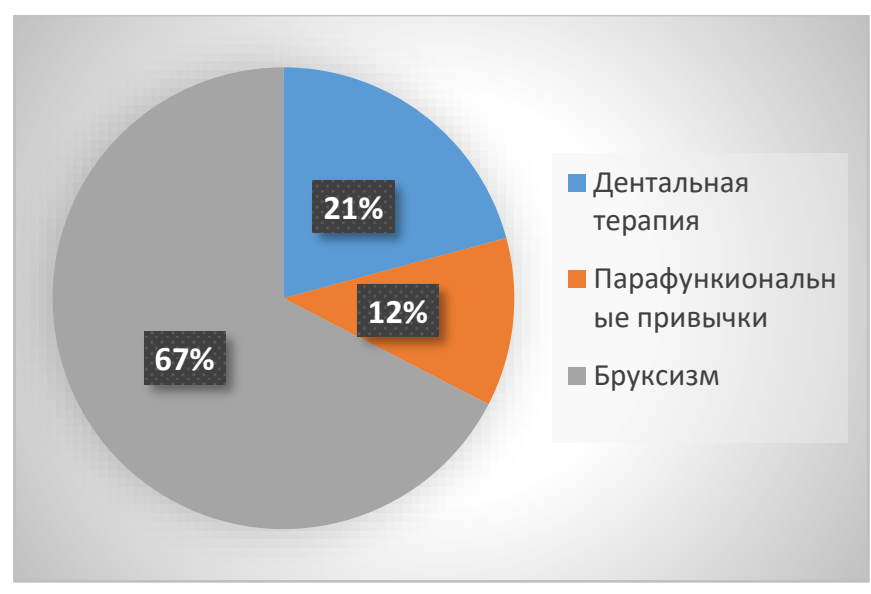

\section{Обсуждение полученных результатов.}

Распространенность нарушений ВНЧС составляет более $40 \%$ в общей популяции и самым раздражающим симптомом у этих
(92.73\%) женщины , 16 (7.27\%) мужчины. Возраст пациентов от 13 до 56 лет (средний возраст 34.5 года). У 12 пациентов (21.8\%) дислокации диска не обнаружено. У 43 пациентов (78.18\%) дислокация диска выявлена. У 28 (50.9 \%) из 55 пациентов дислокация диска сопровождалась редукцией при открывании рта, у 15 (34.88\%) пациентов редукции не выявлялось. пациентов является боль [7,8]. МРТ является методом «золотого стандарта» при нарушениях ВНЧC, так как позволяет выявлять положение суставного диска в положении открытого и закрытого рта [9]. У пациентов с нарушением ВНЧС может присутствовать разнообразная клиническая симптоматика [1,2]. В данное исследование были включены пациенты с жалобами только на боль, с целью выявления насколько боль может быть хорошим индикатором при этих нарушениях. Исследовались пациенты с односторонней болью, так как при двухсторонних болях трудно дать оценку боли по шкале. Из 55 пациентов с болевой симптоматикой $51 \quad(92.73 \%)$ составляли женщины. Warren et al. описывали, что женщины более склонны к болям в области ВНЧС и более склонны к аллодинии [10]. Преобладание женского пола объясняется проноцептивным эффектом эстрадиола на ВНЧС как описывали Wu et al.. Боль является таким субъективным критерием, который варьирует даже в зависимости от пола [11]. Vieira-Queiroz et al. обнаружили, что пациенты c болью зачастую имеют внутреннее нарушение ВНЧС на МРТ [9]. Данное исследование подтверждает эти данные: у 43(78.18\%) из 55 пациентов была выявлена дислокация диска с редукцией или без редукции. Эти данные указывают на то, что 
пациенты страдающие болью как правило имеют внутреннее нарушение ВНЧС. Приблизительно 1/3 пациентов с болью имели нормальные данные МРТ . Таким образом, боль связана не только с внутренним нарушением ВНЧС, а также с личными факторами, и может быть вызвана нарушениями, которые невозможно выявить на MPT [12]. Много литературы подтверждают корреляцию нарушений ВНЧС с этиологией [13]. Было проведено сравнение остроты боли у пациентов с дислокацией диска с редукцией и без редукции на основании шкалы боли. Существенной разницы между этими группами не обнаружено. Таким образом, не обязательным является наличие более острой боли у пациентов с дислокацией диска без редукции, чем с редукцией. В заключение, МРТ по-прежнему является наиболее точным и золотым стандартом для пациентов с болью в области ВНЧС. Тем не менее, нет корреляции между уровнем боли и результатами МРТ.

\section{Финансовый источник: При написании статьи не использовались финансовые ресурсы.}

Конфликт интересов: Нет.

\section{СПИСОК ЛИТЕРАТУРЫ}

1. B de Melo DP, Sousa Melo SL, de Andrade Freitas Oliveira LS, Ramos-Perez FM, Campos PS. Evaluation of temporomandibular joint disk displacement and its correlation with pain and osseous abnormalities in symptomatic young patients with magnetic resonance imaging. Oral Surg Oral MedOral Pathol Oral Radiol 2015; 119: 107-112.

2. Rudisch A, Innerhofer K, Bertram S, Emshoff R. Magnetic resonance imaging findings of internal derangement and effusion in patients with unilateral temporomandibular joint pain. Oral Surg Oral Med Oral Pathol Oral Radiol Endod 2001; 92: 566-571.

3. Emodi-Perlman A, Yoffe T, Rosenberg N, Eli I, Alter Z, Winocur E. Prevalence of psychologic, dental, and temporomandibular signs and symptoms among chronic eating disorders patients: a comparative control study. J Orofac Pain 2008; 22: 201-208.

4. Овчинников, К. А. Изучение височнонижнечелюстного сустава по данным МРТ у пациентов с дисплазией соединительной ткани / Овчинников К. А. // Институт стоматологии. 2016. - No3. - C. 90.

5. Grossmann E, Januzzi E, Iwaki Filho L (2013) $\mathrm{O}$ uso do hialuronato de sódio no tratamento das disfunçõestemporomandibularesarticulares. Rev Dor. 14: 301-306.

6. Комолов, И. С. Магнитно-резонансная томография в оценке влияния смещений суставного диска на формирование болевого синдрома при дисфункции височнонижнечелюстного сустава / Комолов И. С., Васильев А. Ю. // Радиология-практика. - 2018. No2 (68). - C. $20-27$.

7. Ryalat S, Baqain ZH, Amin WM, Sawair F, Samara O, Badran DH. Prevalence of temporomandibular joint disorders among students of the University of Jordan. J Clin Med Res 2009; 1: 158164.

8. Chantaracherd P, John MT, Hodges JS, Schiffman EL. Temporomandibular joint disorders' impact on pain, function, and disability. J Dent Res 2015; 94: 79-86.

9. Vieira-Queiroz I, Gomes Torres MG, de Oliveira-Santos C, Flores Campos PS, Crusoé-Rebello IM. Biometric parameters of the temporomandibular joint and association with disc displacement and pain: a magnetic resonanceimaging study. Int $\mathrm{J}$ Oral Maxillofac Surg 2013; 42: 765-770.

10. Warren MP, Fried JL. Temporomandibular disorders and hormones in women. Cells Tissues Organs 2001; 169:187-192.

11. Wu YW, Bi YP, Kou XX, Xu W, Ma LQ, Wang KW, Gan YH, Ma XC. 17-Beta-estradiol enhanced allodynia of inflammatory temporomandibular joint through upregulation of hippocampal TRPV1 in ovariectomized rats. JNeurosci 2010; 30: 8710-8719.

12. Fujiwara M, Honda $\mathrm{K}$, Hasegawa $\mathrm{Y}$, Hasegawa M, Urade M. Comparison of joint pain in patients diagnosed with and without articular disc displacement without reduction based on the Research Diagnostic Criteria forTemporomandibular Disorders. Oral Surg Oral Med Oral Pathol Oral Radiol 2013; 116: 9-15.

13. Sharma S, Gupta DS, Pal US, Jurel SK. Etiological factors of temporomandibular joint disorders. Natl J Maxillofac Surg 2011; 2: 116-119. 


\section{Gicgah-çənə oynağı disfunksiyası və ağrı simptomları}

\section{Oli-zadə C. K.}

Bakı şəhəri Morkəzi Klinik Xəstวxanasının Diaqnostik Radiologiya şöbəsi

Xülasə : Gicgah-çənə oynağı (GÇO) disfunksiyası tez-tez maqnit rezonans tomoqrafiyası (MRT) ilə aşkar olunan oynaq diskin dislokasiyasıdır. Disfunksiyanın əsas əlaməti ağrıdır. Bu məqalədə GÇO-daki ağrı və disk dislokasiyası arasında bir əlaqə qurulmuşdur.

Açar sözlər : gicgah-çənə oynă̆ının disfunksiyası, maqnit-rezonans tomoqrafiya, ă̆rı.

Disfunction of the temporomandibular joint and pain

\section{Ali-zada J.K. \\ Department of Diagnostic Radiology, Central Clinical Hospital, Baku}

Summary. Temporomandibular joint dysfunction (TMJ) is a disk dislocation that is often detected by magnetic resonance imaging (MRI). The main symptom of dysfunction is pain. In this study, a correlation was made between pain in the TMJ and disk dislocation.

Key words: Internal derangement, magnetic resonance imaging, pain

Müalliflə əlaqə üçün : Oli-zadə Comilə Kamal qızı, Morkəzi Klinika, Baku

E-mail: jamila_alizade@yahoo.com

Rayçi: t.e.d.., prof. Ç. R. Rohimov 